Document downloaded from:

http://hdl.handle.net/10251/145553

This paper must be cited as:

Min, R.; Ortega Tamarit, B.; Nielsen, K.; Bang, O.; Marques, C. (05-2). Bragg Grating Inscription With Low Pulse Energy in Doped Microstructured Polymer Optical Fibers. IEEE Sensors Letters. 2(2):1-4. https://doi.org/10.1109/LSENS.2018.2830804

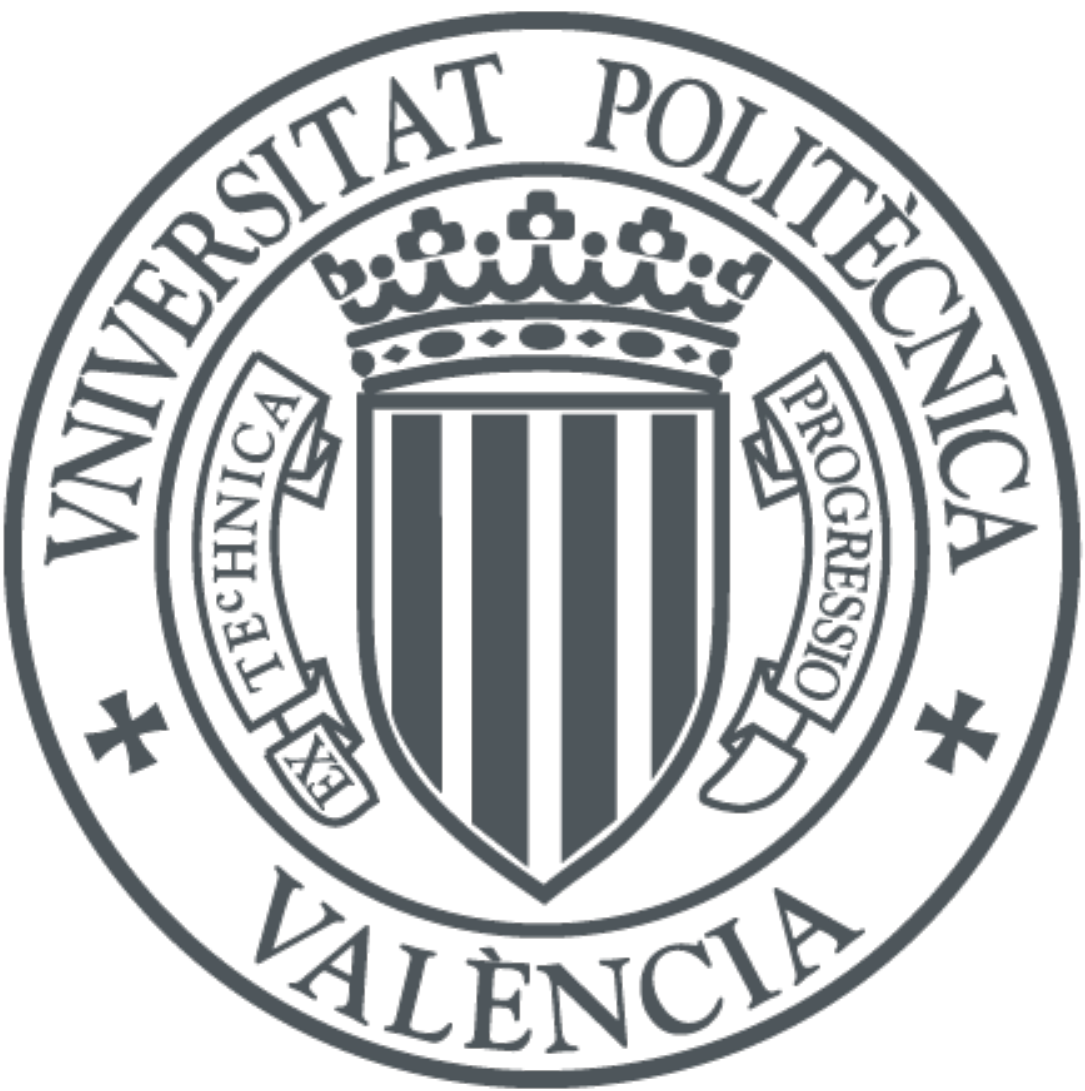

The final publication is available at

https://doi.org/10.1109/LSENS.2018.2830804

Copyright Institute of Electrical and Electronics Engineers (IEEE)

Additional Information 


\title{
Bragg grating inscription with low pulse energy in doped microstructured polymer optical fibers
}

\author{
Rui Min ${ }^{1}$, Beatriz Ortega ${ }^{1}$, Kristian Nielsen ${ }^{2,3}$, Ole Bang ${ }^{2,3}$ and Carlos Marques ${ }^{4}$ \\ ${ }^{1}$ ITEAM Research Institute, Universitat Politècnica de València, Valencia, Spain \\ ${ }^{2}$ DTU Fotonik, Department of Photonics Engineering, Technical University of Denmark, Denmark \\ ${ }^{3}$ SHUTE Sensing Solutions APS, Diplomvej 381, 2800 Kongens Lyngby, Denmark \\ ${ }^{4}$ Instituto de Telecomunicações, Campus Universitário de Santiago, 3810-193 Aveiro, Portugal
}

\begin{abstract}
Received 1 xxx 201x, revised 25 xx 201x, accepted xx xx 201x, published 5 xx 201x, current version xx xxx 201x. (Dates will be inserted by IEEE; "published" is the date the accepted preprint is posted on IEEE Xplore ${ }^{\circledR}$; "current version" is the date the typeset version is posted on Xplore ${ }^{\circledR}$ ).
\end{abstract}

\begin{abstract}
We demonstrate that fiber Bragg gratings (FBGs) can be written in a doped polymer optical fiber (POF) in a low UV pulse energy regime $(60 \mu \mathrm{J} /$ pulse) using a $248 \mathrm{~nm}$ krypton fluoride $(\mathrm{KrF})$ excimer laser system. The total energy density per inscription necessary to obtain Bragg gratings is between $493.6 \mathrm{~mJ} / \mathrm{cm}^{2}$ and $3825 \mathrm{~mJ} / \mathrm{cm}^{2}$, depending on the number of pulses and the pulse energy. The impact of the pulse energy on the growth of the Bragg grating is investigated and it is shown that the $248 \mathrm{~nm}$ light induces a positive refractive index change. This paper demonstrates that FBGs can be obtained in POFs without high pulse energy ( $\mathrm{mJ}$ level) at $248 \mathrm{~nm}$ wavelength, which reduces maintenance costs. Furthermore, we can consider it as a solution to increase the life time of the laser system without high energy still allowing fast and efficient production of the FBGs for sensing applications.
\end{abstract}

Index Terms_-Integrated fiber optical devices, optical fiber, fiber Bragg grating sensors.

\section{INTRODUCTION}

During the last two decades polymer optical fibers (POFs) have attracted the attention of many researchers due to the continuous reduction of the transmission attenuation among other reasons [1]. Due to the advantage of polymers over silica such as low Young' $\mathrm{s}$ modulus and biological compatibility, polymer optical fiber Bragg gratings (POFBGs) have been considered as a promising technology for sensing [2] and short-range optical communications [3]. The first POFBG based on PMMA was reported in 1999 [4]. Since then, different kind of polymer materials such as PMMA, CYTOP, TOPAS, Zeonex or even polycarbonate have been used to fabricate Bragg gratings [5-10]. However, PMMA is known as the most used among all of the materials and high quality FBGs have been fabricated in pure PMMA microstructured polymer optical fiber (mPOF) using a $325 \mathrm{~nm} \mathrm{He}-\mathrm{Cd} \mathrm{CW}$ laser, initially using 2 hours [5] and recently using less than 7 minutes [11]. Due to the low photosensitivity of pure PMMA, a photosensitizer such as trans-4-stilbenemthanol or benzyl dimethyl ketal (BDK) can be added in the fiber core or cladding to improve it [12-14]. Compared with pure PMMA, BDK-doped PMMA presents two absorption bands (one very pronounced at $250 \mathrm{~nm}$ region and other at $320-350 \mathrm{~nm}$ region) with evident photosensitivity enhancement at $248 \mathrm{~nm}$ region [13]. The addition of a dopant to the non-fully polymerized PMMA allows the selection of the wavelength needed to induce photopolymerization, where the wavelength of $248 \mathrm{~nm}$ can be used for the BDK as a photoinitiator as discussed in [13]. In this way, Luo et al reported the first Bragg grating in a BDK- doped core PMMA POF using a 355nm laser [13]. Then a $\sim 99 \%$ reflective POFBG was obtained in a BDK-doped core PMMA mPOF after 13 min of irradiation with a $325 \mathrm{~nm}$ laser [15]. In 2017, a 400 $\mathrm{nm}$ femtosecond pulsed laser was used for fast irradiation to produce FBGs in BDK-doped mPOF with just 40 seconds [16], where different UV powers were employed to obtain different grating responses.

Initially, $325 \mathrm{~nm}$ was demonstrated as the optimal wavelength to inscribe POFBGs, and $248 \mathrm{~nm}$ wavelength was not considered suitable for POFBG fabrication due to periodic ablation mentioned by Peng et al in 1999 [17]. In 2000, the refractive index modification achieved with a $248 \mathrm{~nm}$ laser was investigated on PMMA chips for integrated-optical waveguides at low fluence $\left(\mathrm{I}=17 \mathrm{~mJ} / \mathrm{cm}^{2}\right)$ and low frequency $(5 \mathrm{~Hz})$ [18]. A $248 \mathrm{~nm}$ laser was employed to successfully inscribe the first POFBG using $3 \mathrm{~mJ}$ pulses in few seconds [19].

With the aim of reducing fabrication times, such a $248 \mathrm{~nm}$ laser was later employed to fabricate FBGs in BDK doped fiber with a single UV laser pulse with a high pulse energy of $6.3 \mathrm{~mJ}(974$ $\mathrm{mJ} / \mathrm{cm} 2$ ) [20]. After irradiation, the strength of the grating continues growing for several minutes; similar to previously reported behavior in dye-doped PMMA optical fiber using $325 \mathrm{~nm}$ laser based grating inscription setup [21]. However, according to previous results [20], the irradiation of two or three ultraviolet pulses leads to some decrease in the induced index change so different UV pulse energy level has to be explored in order to optimize the fabrication process.

In this paper, we demonstrate the use of low pulse energy (60 $\mathrm{uJ} /$ pulse) to get a grating with $40 \%$ reflectivity in 90 pulses, of $15 \mathrm{~ns}$ duration each one. This work shows the impact of the pulse energy 
and the total UV energy on the grating growth. The fabricated grating shows a positive refractive index change and stability after fabrication which is very important and different from FBGs written with higher energy pulses recently reported in [20]. We also demonstrated energy efficient grating fabrication using 4 pulses of $200 \mu \mathrm{J}$ per pulse, achieving a suitable grating transmission of about $7.5 \mathrm{~dB}$.

\section{BRAGG GRATING INSCRIPTION}

\section{A. Inscription setup}

A PMMA mPOF with 3 rings of holes and a BDK-doped core was used to inscribe Bragg gratings in this work. The three ring cladding microstructure has a hole-to-pitch ration of 0.47 with an average hole diameter of $1.74 \mu \mathrm{m}$ and an average pitch of $3.70 \mu \mathrm{m}$ [15], which makes it close to endlessly single-moded [22]. A cross-section image of the fiber is shown in the inset of Fig. 1. A Coherent Bragg Star Industrial-LN krypton fluoride $(\mathrm{KrF})$ excimer laser system operating at $248 \mathrm{~nm}$ wavelength with a $1 \mathrm{~Hz}$ repetition rate was employed for the Bragg grating inscription. The laser beam profile was measured as a rectangular Tophat function of $6.0 \times 1.5 \mathrm{~mm}^{2}$ size and $2 \times 1 \mathrm{mrad}^{2}$ divergence. It was focused onto the fiber core utilizing a plano-convex cylindrical lens (Newport CSX200AR.10) with focal length of $20 \mathrm{~cm}$. The effective spot size of the beam on the fiber surface is $20.0 \mathrm{~mm}$ in width and $32.4 \mu \mathrm{m}$ in height. A slit was employed to control the width of the beam as shown in Fig. 1. The UV light was passed through a $567.8 \mathrm{~nm}$ pitch phase mask over a $5 \mathrm{~mm}$ fiber length.

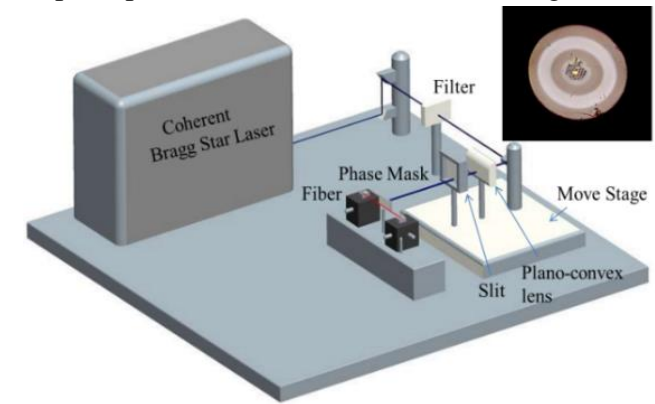

Fig. 1. Experimental setup for POFBG inscription. Inset: mPOF crosssection image.

\section{B. Grating growth performance}

The reflected power spectrum was monitored during irradiation by using a super luminescent diode (Superlum SLD-371-HP1) and an optical spectrum analyzer (Yokogawa AQ6373B) with $0.02 \mathrm{~nm}$ resolution bandwidth. A linear step ND filter (Thorlabs NDL-10S-4) and a glass slide (can decrease $90 \%$ of $248 \mathrm{~nm}$ UV power beam) were used to control the pulse energy. An energy power meter (packaged with Coherent Bragg Star Industrial-LN KrF excimer laser system) was used to measure pulse energy with $\pm 1.0 \%$ accuracy from $\mathrm{nJ}$ to $\mathrm{J}$ and the pulse energy fluctuates with $\pm 5 \%$ per pulse.

Fig. 2 shows the post-inscription POFBG growth when it has been fabricated using 5 pulses of $200 \mu \mathrm{J}$ energy per pulse at $1 \mathrm{~Hz}$ repetition rate (6 times less than the energy used in previous work using a single UV pulse [20]). A red shift behavior was observed and its reflected power keeps increasing for more than 100 seconds. No grating was achieved with only 1 pulse of this level of pulse energy.
It's worth noting that a grating with a strength of about $5 \mathrm{dBm}$ in reflection has appeared after five $200 \mu \mathrm{J}$ pulses, which is comparable to the strength obtained with only one pulse of high energy reported in [20]. The difference is that at high pulse energy levels, the grating strength will decrease during the second pulses, as observed and discussed in [20], where the authors did not find an explanation for this behaviour. However, it can be justified by excessive reaction (due to the core damage for long time UV exposure [13]) with high total UV energy received, which is a similar behavior as was previously reported in [13, 21]. However, in our case Fig. 2 shows that the grating growth continued after five low energy pulses with $1 \mathrm{~Hz}$. A potential reason is that this low power pulse of $200 \mu \mathrm{J}$ has a gradual refractive index change on the polymer when compared to the abrupt change observed for high energy pulses and after 5 pulses we can reach to an adequate index change in the fiber core.

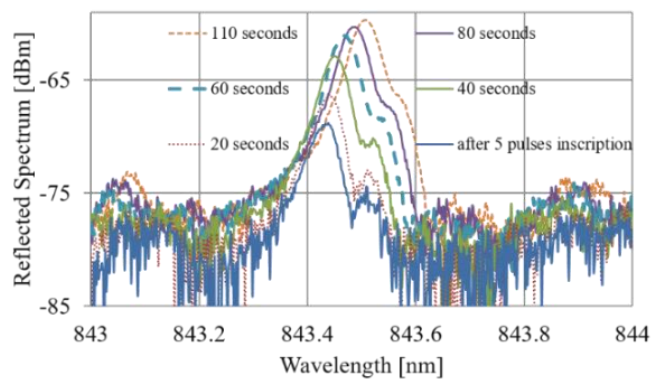

Fig. 2. Post-inscription grating growth of a POFBG fabricated using 5 pulses of $200 \mu \mathrm{J}$ energy per pulse at $1 \mathrm{~Hz}$ repetition rate.

In order to evaluate the lowest pulse energy suitable to fabricate Bragg gratings, a series of different tests were performed. Figure 3 shows the grating growth during irradiation of $60 \mu \mathrm{J}$ energy pulses at $1 \mathrm{~Hz}$ repetition rate as the number of irradiated pulses is increased up to 90 pulses. The grating appears after 20 pulses and its strength keeps increasing as the number of pulses increases. After 90 pulses the laser system was turned off and the reflected power of the grating kept relatively stable - a different behavior when compared with the result presented before in Fig. 2. Figure 4 shows the transmission response of such gratings irradiated with a different number of $60 \mu \mathrm{J}$ pulses. A transmission rejection band of $2.2 \mathrm{~dB}$, or $40 \%$ equivalent reflectivity, was obtained with 90 pulses. Additional tests were carried out in order to check the stability of very weak gratings fabricated with 20 pulses and the reflected power measurement of the grating was very stable. Also, tests were performed with $32 \mu \mathrm{J}$ energy pulses however, it did not allow getting any grating, even trying with a large number of pulses, i.e. 600 pulses.

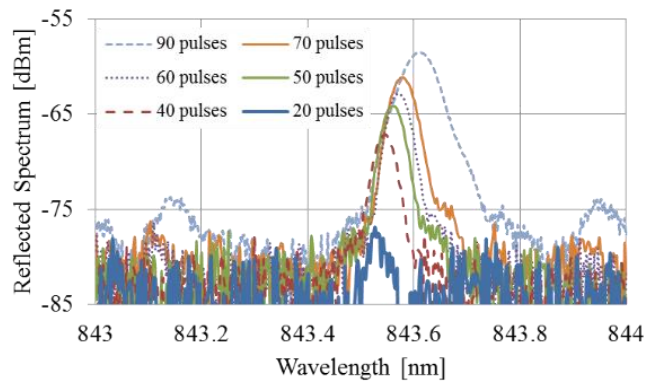

Fig. 3. Reflection spectrum obtained with different number of pulses (1 $\mathrm{Hz}$ repetition rate) using a pulse energy of $60 \mu \mathrm{J}$. 
Our results indicate that a minimum pulse energy is need for a successful grating inscription, which after several tests is estimated as $60 \mu \mathrm{J}$ of energy per pulse. Importantly, for the pulse energy levels of $60 \mu \mathrm{J}, 124 \mu \mathrm{J}$, and $200 \mu \mathrm{J}$, the gratings grew until a high level of reflection with no similar phenomenon happening as described in [20], where the second and third pulses was observed to reduce the reflected power of the grating [13, 20, 21]. A decrease in reflected power with increasing UV irradiation time was observed both with a PMMA fiber under $325 \mathrm{~nm}$ UV pulse irradiation $(5 \mathrm{~ns}, 10 \mathrm{~Hz}$ ) [21] and a BDK-doped PMMA fiber under $355 \mathrm{~nm}$ pulsed laser irradiation [13]. The photosensitivity mechanisms of PMMA are still under research and the refractive index changes can be introduced by photocrosslinking, photo degradation, or by photo polymerization [20]. During the FBG inscription, BDK acts as a photo-initiator and is activated by a transition within the molecular orbital of the $>\mathrm{C}=\mathrm{O}$ group followed by $\alpha$-splitting to produce free radicals. When illuminated by UV light, a series of reactions could happen as described in [13], where PMMA doped with BDK shows more than 15 times higher UV absorption compared with pure PMMA at 250 nm wavelength.

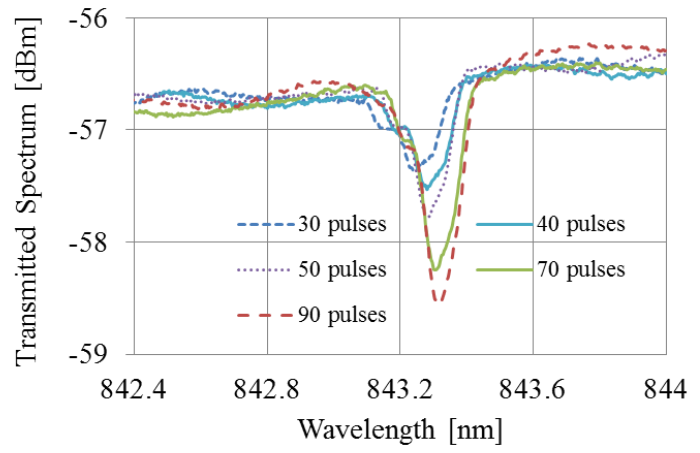

Fig. 4. Transmission spectrum for $30,40,50.70$, and 90 pulses $(1 \mathrm{~Hz}$ repetition rate) using a pulse energy of $60 \mu \mathrm{J}$.

As shown in Table 1, the number of pulses required to achieve Bragg gratings with different pulse energies $(60 \mu \mathrm{J}, 124 \mu \mathrm{J}, 200 \mu \mathrm{J}$, $500 \mu \mathrm{J}$ and $2000 \mu \mathrm{J}$ ) varies significantly. It is obvious that high pulse energy contributes to a shorter irradiation time since pulse energies of $200 \mu \mathrm{J}, 500 \mu \mathrm{J}$ and $2000 \mu \mathrm{J}$ require 4,2 and 1 pulses, respectively. Figure 5 shows the stability of the gratings specified in Table 1 during an hour after irradiation in terms of wavelength shift and reflection band of the grating. All wavelengths indicate a red shift, as is expected due to the photo-polymerization mechanism [14].

Table 1. Performance of the POFBG for different pulse energies and number of pulses.

\begin{tabular}{ccccc}
\hline $\begin{array}{c}\text { Pulse } \\
\text { energy } \\
(\mu \mathrm{J})\end{array}$ & $\begin{array}{c}\text { Energy density } \\
\text { per pulse } \\
\left(\mathrm{mJ} / \mathrm{cm}^{2}\right)\end{array}$ & $\begin{array}{c}\text { Total } \\
\text { pulses }\end{array}$ & $\begin{array}{c}\text { Reflection } \\
\text { band } \\
(\mathrm{dB})\end{array}$ & $\begin{array}{c}\text { Energy density } \\
\text { per inscription } \\
\left(\mathrm{mJ} / \mathrm{cm}^{2}\right)\end{array}$ \\
\hline 60 & 37.0 & 90 & 22 & 3333.3 \\
124 & 76.5 & 50 & 18 & 3825 \\
$\mathbf{2 0 0}$ & $\mathbf{1 2 3 . 4}$ & $\mathbf{4}$ & $\mathbf{2 4}$ & $\mathbf{4 9 3 . 6}$ \\
200 & 123.4 & 5 & 23 & 617 \\
500 & 308.6 & 2 & 20 & 617.2 \\
2000 & 1234.6 & 1 & 20 & 1234.6 \\
\hline
\end{tabular}

Analyzing Table 1, we can notice a tradeoff between pulse energy and energy density per inscription since the lowest energy density per inscription was not obtained when the lowest pulse energy is applied.

\section{Grating monitor during one hour}

The reflected power changes are more diverse, where Fig. 5 (b) indicates that grating with $60 \mu \mathrm{J}$ pulse energy shows a slight decreasing less than $1 \mathrm{~dB}$ in 60 min and gratings with $200 \mu \mathrm{J}$ and 500 $\mu \mathrm{J}$ show the trend of growth less than $3 \mathrm{~dB}$.

In general, these results show a suitable stability of both the center wavelength and the reflectivity of the POFBGs. The reflection band changes do not show an obvious relationship with the pulse energy. However, it is to be expected that the reflected power changes have a relationship with the total UV energy received and the BDK dopant concentration in the fiber.
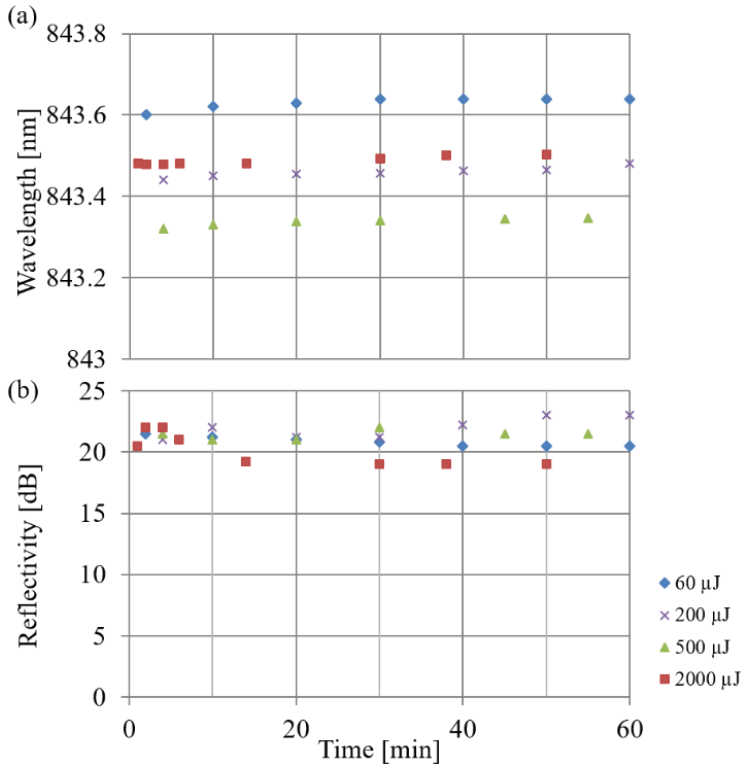

Fig. 5. One-hour monitor after irradiation: a) wavelength response, b) reflectivity.

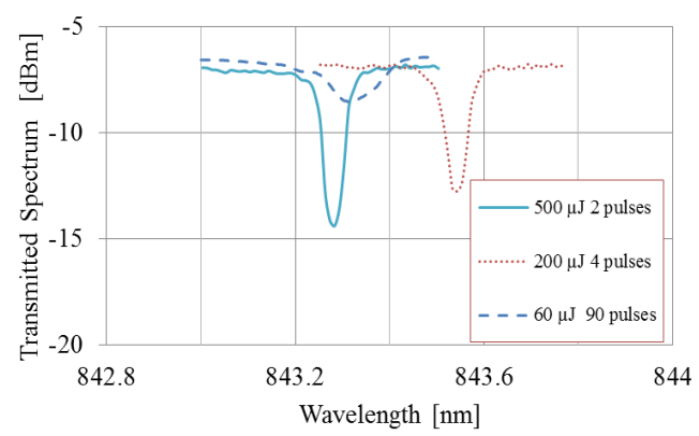

Fig. 6. Transmission spectrum of gratings obtained with different pulse energy and number of pulses.

In order to provide a better insight into POFBGs fabricated by irradiation with low UV pulse energy, we obtained some results based on the transmitted power spectra as shown in Fig. 6. Three of the POFBGs given in Table 1 (90 pulses with $60 \mu \mathrm{J}$ energy, 4 pulses with $200 \mu \mathrm{J}$ energy, and 2 pulses with $500 \mu \mathrm{J}$ energy) were analyzed and their transmission spectrum collected. The transmission dip of these POFBGs are $2.2 \mathrm{~dB}, 5.7 \mathrm{~dB}$, and $7.5 \mathrm{~dB}$, respectively. This result 
indicates a better performance when compared with BDK doped fiber irradiation with $400 \mathrm{~nm}$ femtosecond laser [16]. In [16] with $1 \mathrm{~mW}$ during 100 seconds a grating with a $0.2 \mathrm{~dB}$ transmission dip. In our experiment we can achieve gratings from $2 \mathrm{~dB}$ to $8 \mathrm{~dB}$ in transmission. From these results, the lowest energy density needed to inscribe a grating is $493.6 \mathrm{~mJ} / \mathrm{cm}^{2}, 2$ times less than reported in [20], where a single UV pulse was applied providing an energy density of 974 $\mathrm{mJ} / \mathrm{cm}^{2}$. The absorption performance at $250 \mathrm{~nm}$ and $400 \mathrm{~nm} \mathrm{UV}$ wavelength may be able to explain this better performance [13].

As well known, strain characterization is also required for potential sensing applications as presented in many works in literature. For this purposes, the grating with $60 \mu \mathrm{J}$ and 90 pulses was placed on an XYZ translation stage. The central wavelength shift was monitored when the strain was changed from 0 to $1.1 \%$ at room temperature, as shown in Fig. 7. The wavelength shift of $8.28 \mathrm{~nm}$ was observed with respect to the unstrained fiber, indicate a linear strain sensitivity of $0.753 \pm 0.002 \mathrm{pm} / \mu \varepsilon$, similar with the previous FBGs in annealed POFs [23].

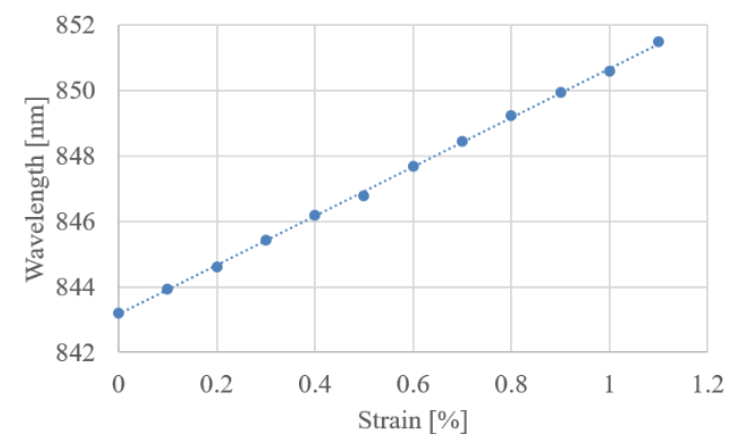

Fig. 7. Central wavelength shifts vs. strain.

\section{CONCLUSION}

In this letter we demonstrated that with low UV power (60 $\mu \mathrm{J} /$ pulse) we can achieve a suitable grating with a $2.2 \mathrm{~dB}$ dip in transmission and a reflectivity of $22 \mathrm{~dB}$, which makes them suitable for many sensing applications. Analyzing the effect of different pulse energies and total UV energy on the quality of the grating, we found that with $200 \mu \mathrm{J}$ pulse energy we can achieve a suitable grating transmission dip of about $7.5 \mathrm{~dB}$ and a grating reflectivity of $24 \mathrm{~dB}$ with just 4 pulses, the most energy-saving way to achieve a reasonable grating with an energy density of $493.6 \mathrm{~mJ} / \mathrm{cm}^{2}$ for each inscription. The demonstrated gratings could be obtained without high pulse energy, which avoids high maintenance costs. This research can be useful for future investigations of different kind of Bragg grating devices fabrication for sensing fields in order to reduce the energy waste and pay attention to the minimum UV energy and total energy received. In addition, we will optimize the number of pulses for energies from 60 to $200 \mu \mathrm{J}$ in order to get a detailed optimization between the pulse energy and number of pulses with the aim to achieve the lowest energy density per inscription.

\section{ACKNOWLEDGMENT}

This work was supported by UID/EEA/50008/2013, SFRH/BPD/109458/2015, KJCXZD201703 and GVA PROMETEO 2017/103.

\section{REFERENCES}

[1] Koike, Yasuhiro, and Makoto Asai (2009), "The future of plastic optical fiber," $N P G$ Asia Materials 1.1, pp 22-28.

[2] K. Peters (2010), "Polymer optical fiber sensors - a review," Smart Materials and Structures, 20(1), 013002.

[3] O. Ziemann, J. Krauser, P. E. Zamzow, W. Daum (2008), "POF handbook: optical short range transmission systems," Springer Science \& Business Media.

[4] Z. Xiong, G.D.Peng, B. Wu, P. Chu (1999), "Highly tunable Bragg gratings in singlemode polymer optical fibers," IEEE Photon. Technol. Lett., vol.11, pp 352-354.

[5] D. Sáez-Rodríguez, K. Nielsen, O. Bang, D. J. Webb (2014), "Photosensitivity mechanism of undoped poly (methyl methacrylate) under UV radiation at $325 \mathrm{~nm}$ and its spatial resolution limit," Opt. Lett., vol. 39, pp. 3421-3424.

[6] A. Lacraz, M. Polis, A. Theodosiou, C. Koutsides, K. Kalli, (2015), "Femtosecond laser inscribed Bragg gratings in low loss CYTOP polymer optical fiber," IEEE Photon. Technol. Lett., vol. 27, pp 693-696.

[7] W. Yuan, L. Khan, D. J. Webb, K. Kalli, H. K. Rasmussen, A. Stefani, O. Bang (2011), "Humidity insensitive TOPAS polymer fiber Bragg grating sensor," Opt. Express, vol.19, pp 19731-19739.

[8] I.P. Johnson, W. Yuan, A. Stefani, K. Nielsen, H.K. Rasmussen, L. Khan, D.J. Webb, K. Kalli, O. Bang, (2011) "Optical fibre Bragg grating recorded in TOPAS cyclic olefin copolymer," Electron. Lett., vol.47, pp 271-272.

[9] G. Woyessa, A. Fasano, C. Markos, A. Stefani, H. K. Rasmussen, O. Bang (2017), "Zeonex microstructured polymer optical fiber: fabrication friendly fibers for high temperature and humidity insensitive Bragg grating sensing," Opt. Mat. Express, vol.7, pp 286-295.

[10] A. Fasano, G. Woyessa, P. Stajanca, C. Markos, A. Stefani, K. Nielsen, H.K. Rasmussen, K. Krebber, O. Bang, (2016) "Fabrication and characterization of polycarbonate microstructured polymer optical fibers for high-temperature-resistant fiber Bragg grating strain sensors", Opt. Mat. Express, vol.6, pp 649-659.

[11] I.-L. Bundalo, K. Nielsen, C. Markos, O. Bang, (2014) "Bragg grating writing in PMMA microstructured polymer optical fibers in less than 7 minutes", Opt. Express, vol.22, pp 5270-5276.

[12] X. Hu, C. F. J. Pun, H. Y. Tam, P. Mégret, C. Caucheteur (2014), "Highly reflective Bragg gratings in slightly etched step-index polymer optical fiber," Opt. Express, vol.22, pp 18807-18817.

[13] Y. Luo, Q. Zhang, H. Liu, G. D. Peng (2010), "Gratings fabrication in benzildimethylketal doped photosensitive polymer optical fibers using $355 \mathrm{~nm}$ nanosecond pulsed laser," Opt. Lett., vol. 35, pp 751-753.

[14] D. Kowal, G. Statkiewicz-Barabach, P. Mergo, W. Urbanczyk (2014), "Microstructured polymer optical fiber for long period gratings fabrication using an ultraviolet laser beam," Opt. Lett., vol.39, pp 2242-2245.

[15] D. Sáez-Rodríguez, K. Nielsen, H. K. Rasmussen, O. Bang, DJ. Webb (2013), "Highly photosensitive polymethyl methacrylate microstructured polymer optical fiber with doped core," Opt. Lett., vol. 38, pp 3769-3772.

[16] X. Hu, G. Woyessa, D. Kinet, J. Janting, K. Nielsen, O. Bang, C. Caucheteur (2017), "BDK-doped core microstructured PMMA optical fiber for effective Bragg grating photo-inscription” Opt. Lett., vol. 42, pp. 2209-2212.

[17] G. D. Peng, Z. Xiong, P. L. Chu (1999), "Photosensitivity and gratings in dye-doped polymer optical fibers" Optical Fiber Technology, vol.5, pp 242-251.

[18] C. Wochnowski, S. Metev, and G. Sepold (2000), "UV-laser-assisted modification of the optical properties of polymethylmethacrylate," Appl. Surf. Sci. vol 154, pp 706-711.

[19] R. Oliveira, L. Bilro, R. Nogueira (2015), "Bragg gratings in a few mode microstructured polymer optical fiber in less than 30 seconds" Opt. Express, vol. 23, pp 10181-10187.

[20] A. Pospori, C. A. F. Marques, O. Bang, D. J. Webb, P. André (2017), "Polymer optical fiber Bragg grating inscription with a single UV laser pulse" Opt. Express, vol. 25, pp 9028-9038.

[21] H. B. Liu, H. Y. Liu, G. D. Peng, and P. L. Chu (2004), "Novel Growth Behaviors of Fiber Bragg Gratings in polymer optical fiber under UV Irradiation with low power," IEEE Photon. Technol. Lett. vol.16, pp 159-161.

[22] B. Kuhlmey, R. C. McPhedran, and C. M. de Sterke (2002), "Modal cutoff in microstructured optical fibers," Opt. Lett., vol. 27, pp 1684-1686.

[23] A. Pospori, C. A. F. Marques, D. Sáez-Rodríguez, K. Nielsen, O. Bang, \& D. J. Webb (2017), "Thermal and chemical treatment of polymer optical fiber Bragg grating sensors for enhanced mechanical sensitivity." Optical Fiber Technology, vol. 36, pp 68-74. 